\title{
Construction Techniques in Crossing Water-rich Sand Stratum of Deep Buried Large Tunnels
}

\author{
Chao $\mathrm{Li}^{1, \mathrm{a}^{*}}$ and Mingzhu Zhang ${ }^{2, \mathrm{~b}}$ \\ ${ }^{1}$ Department of Railway Engineering, Liaoning Railway Vocational and Technical College, Jinzhou, \\ China \\ ${ }^{2}$ The 5th Engineering Co., LTD, China Railway 16th Bureau Group, Tangshan, China

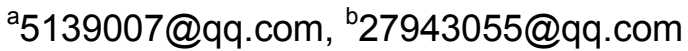 \\ *The Corresponding author
}

\begin{abstract}
Keywords: Engineering of drawing water from Datong River into huanshui river; Horizontal rotary-jet grouting; Disposal of landslide; Water-rich sand stratum
\end{abstract}

\begin{abstract}
As a subdivision and backbone project of engineering of drawing water from Datong River into Huanshui River, the water transfer for main channel project is designed to transfer water from Datong River to Huangshui River, with the total amount of $3.6 \times 108 \mathrm{~m}^{3}$ in a short-term and $7.5 \times 108 \mathrm{~m}^{3}$ in a long-term. The project scale is large II . It is determined to be 2-level for main structure, 3-level for secondary structure and 4-level for temporary structure. The diversion tunnel, which is a non-pressure tunnel to draw water, is $24165.83 \mathrm{~m}$ in length. The ground elevation of tunnel axis is $2943 \sim 4020 \mathrm{~m}$, the maximum and mean burial depths are $1100 \mathrm{~m}$ and about $480 \mathrm{~m}$ respectively, so that it is a deep and long tunnel, which is constructed with TBM, with 5m for diameter, 2955.6 and 2941.7 respectively for elevation of inlet floor and outlet floor. The designed flow of water diversion is $35 \mathrm{~m}^{3} / \mathrm{s}$, longitudinal slope is $\mathrm{i}=0.00054529$, and the maximum flow velocity within the tunnel is $2.24 \mathrm{~m} / \mathrm{s}$.
\end{abstract}

\section{Introduction}

It is more and more common for the regional geological faults being penetrated with the increase of long tunnels during modern constructions, but such geological faults are abundant in underground water from which the water burst, sand boil and mud burst are easily resulted, and the covering layers of some tunnels are not large enough and cannot satisfy the requirements for method of surface consolidation by grouting, so that the reinforcement can only be completed in the tunnel through methods of advance consolidation grouting with full fault surface, advance grouting with small pipe and freeze. However, for water-rich sand layer with large burial depth, the grouting effect is unstable due to dense property, low coefficient of permeability and bad availability of grouting. Also it spends more and takes long time to apply the freezing method.

Therefore, it is more effective to stop water and prevent quicksand for the water-rich sands through rotary-jet grouting construction in the tunnel, but sometimes the complete water-stop curtain cannot form due to worse occlusion among piles so that the advance grouting with small pipe is required to replenish. Such steps have been taken to dispose the landslide during the water transfer for main channel project of engineering of drawing water from Datong River into Huanshui River, which have helped to pass through the areas better.

\section{Overview}

The project, i.e. the water transfer for main channel project of engineering of drawing water from Datong River into Huanshui River, was firstly constructed by China Railway Tunnel Stock Co., Ltd. 
which only tunneled $365 \mathrm{~m}$ to location of $\mathrm{K} 16+775$ from $\mathrm{K} 17+140$ in accumulation from 1 st fault on April 3, 2008 to 10th fault on July 23, 2010 due to extremely bad geological conditions.

Later, on March 3, 2011, China Railway Tunnel Stock Co., Ltd. subcontracted the construction work of the rest sections to Italy CMC, which proposed to take the method of tunnel surrounding + drilling and blasting work for full fault surface + TBM stepping, but only excavated to pile mark of K16+758.5 and tunneled $16.5 \mathrm{~m}$ for the main tunnel until October 25, 2013 when subcontracting to out unit. The bypass tunnel surrounding TBM have suffered from the landslip for many times, for this reason, CMC transferred the disposal work of landslip to our unit to construct.

\section{Geological Conditions}

This section penetrates the F5 fault surface which is also called fault of southern Da Banshan. Such fault spreads in NWW form up to $500 \mathrm{~km}$ to be a long and deep fault surface and forms to be the boundary between fault-fold zone of northern Qilian Mountain and middle up warping zone of Qilian Mountain. The fault zone had been formed to be an active peak on Precambrian system and later controlled the spreading of geosyncline of northern Qilian Mountain and had effects on the Triassic system. The performances were presented with fractured thrust faults, $290^{\circ} \sim 305^{\circ}$ of strike and $50 \sim$ $60 \mathrm{~m}$ width of fault. The fault emerges on the edge of Ning-Zhang Highway and west of Pi Tiaozhang, and spreads to metamorphic series of Proterozoic on south and schist, slates of Silurian system and intrusive rock of Caledonian on north. The width of the fault surface and affected fracture zone is up to $70 \sim 100 \mathrm{~m}$.

The fault of southern Da Banshan, which possesses the feature of multi-phase activity, is a long and deep surface in a large scale in the zone of engineering. The up warping zone of Da Banshan and its western part suffered from twice earthquakes with 5 Richter scale in 1925 and 1929 respectively, and 4.7 Richter scale for southeast side in 1963, but the fracturing phenomenon was not obvious for the quaternary strata along the line.

Our unit is responsible for the section penetrating the fault surfaces, in which the rocks are fillings, including majority of cataclasite and some mylonite, mixing with fault gouge. The parent rock is the conglomerate mixing with a small amount of argillaceous siltstone, and the conglomerate is argillaceous cement and $0.4 \sim 0.5 \mathrm{~cm}$ in diameter, part of which will be kaolinization under the action of thermal force. The rocks are extremely soft with fragile feature, low strength and abundant underground water, and the phenomenon of kaolinization is serious. The surrounding rock generates the large extent of deformation and fast rate during excavation, resulting in serious landslide, and mud and water mixture.

\section{Construction Scheme}

Selection of Scheme. According to the aforesaid geological conditions of excavation, the main component of this landslide is extruded and dense water-rich sands, the application of method of advance consolidation grouting will result in small amount of grouting and bad consolidation effect, and the excavation work will still encounter water burst and sand boil.

In case of this, this section is proposed to take the horizontal rotary-jet grouting technology with high pressure to support in advance in order to avoid water burst and sand boil due to insufficient strength of advance support. On the basis of work space and construction progress, the method of horizontal rotary-jet grouting pile with $600 \mathrm{~mm}$ in diameter, $400 \mathrm{~mm}$ interval, $500 \mathrm{~mm}$ beyond of designed contour line for hole location, $20 \mathrm{~m}$ length of each rotary jet grouting and $15 \mathrm{~m}$ of excavation is determined to apply.

Process Principle. The horizontal rotary-jet grouting pile, which is powered by high pressure pump, sprays the grout prepared through drill pile and nozzle of horizontal drilling machine into the earth, 
cuts the sands within a certain range while the nozzle slowly rotates and draws back, and removes the moisture and gas in the sands and occupies the position, applies the cementing material to stir and mix surrounding materials to form piles which can obviously improve the strength and stability of sands and form closed horizontal rotary jet grouting curtain to prevent quicksand and water penetration.

\section{Technical Process}

Construction Machinery. The main machinery includes XPB-90e high pressure grouting pump and $\mathrm{XY}$

-2pc geological drilling rig.

Construction Preparation. The $\mathrm{C} 25$ concrete shall be used to construct the wall for grouting with thickness of $50 \mathrm{~cm}$ on the tunnel face in order to ensure effect of grouting. And then drill holes on the wall for grouting according to the layout of hole location, install the orifice pipe ( $\Phi 108$ seamless steel tube) into the hole, and block cracks between the orifice pipe and the wall for grouting with cement paste.

Preparation of Grout. The grouting shall be carried out by cement grout with water cement ratio of $1: 1$.

Drilling and Grouting. We first drill holes, of which the external angle is $3 \sim 5^{\circ}$ and diameter is $110 \mathrm{~mm}$, with the geological drilling machine according to hole layout, and then inject the cement grout prepared with high pressure grouting pump into the high pressure pipe to conduct the rotary jet grouting work with pressure of $20 \mathrm{MPa} \sim 25 \mathrm{MPa}$. The rotary jet grouting shall be conducted from bottom to top with the principle of encryption, i.e. simple holes first and then double holes. We step forward $0.5 \mathrm{~m}$ for retreating $1 \mathrm{~m}$ each time in order to ensure better occlusion among piles to improve effect of rotary jet grouting, and strictly control the speed to ensure no more than $1 \mathrm{~m} / \mathrm{min}$ in terms of astern speed during the rotary jet grouting.

The technical staff on duty shall strictly check whether the grouting flow, pressure and rotary astern speed are in accordance with the design requirements or not during the rotary jet grouting, and record at any time. They shall check the block in the hole once occurring reverse and abnormal grouting.

Wash Hole Sealing and Device. Discharge the sealing device outside the orifice pipe after stopping rotary jet grouting, rapidly remove the drill and close the ball valve.

Wash the device after completing grouting for all holes.

Effect Inspection. The diameters of disposed horizontal rotary-jet grouting piles during the excavation are more than $600 \mathrm{~mm}$ and most occlusions are good, which have effectively improved conditions of surrounding rocks and overcome the water burst and sand boil. A large scale of water burst changes to water drop during the excavation, and the sections suffered from landslide are finally passed through safely and successfully due to application of advance pipe shed to pre-reinforce for local parts with bad effect of occlusion. The monitoring tunnel convergence deformation is satisfied. As shown in Fig. 1. 


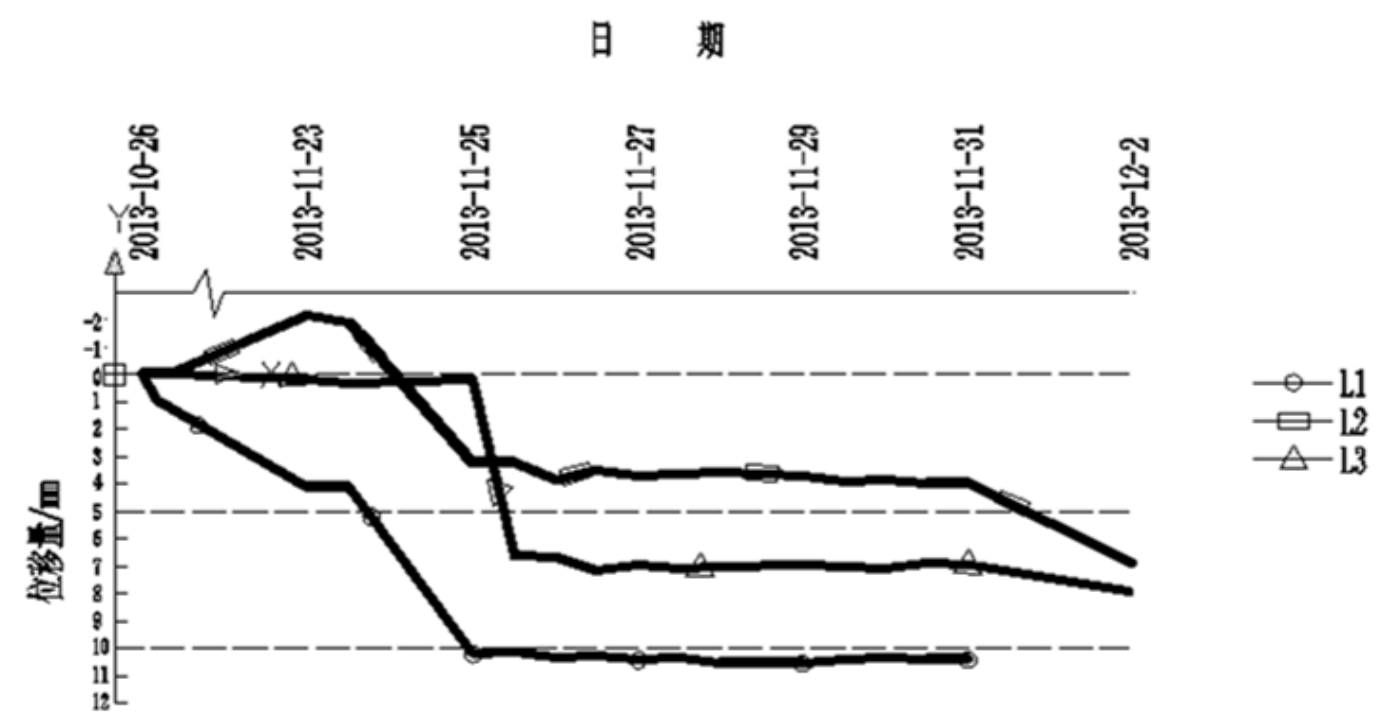

Figure 1. Monitoring tunnel convergence deformation

\section{Summary}

In water-rich sands with large covering layer, simple application of grouting with large pipe shed easily results in water burst and sand boil during the excavation due to dense sands and worse effect of grouting, which is not beneficial to safety control, but the application of horizontal rotary-jet grouting piles has successfully and effectively guaranteed safety of construction work. Now the sections we responsible for have successfully penetrated F5 fault surface (southern Da Banshan), which has created good conditions for assembly of TBM and completion of engineering of drawing water from Datong River into Huanshui River.

It indicates that the application of horizontal rotary-jet grouting piles in water-rich sands is feasible to be as advance support of tunnels, and provide reference for future similar tunnel projects.

\section{Acknowledgements}

Project supported by the Research Foundation of Education Bureau of Liaoning Province, China (Grant No.L2015311).

\section{References}

[1] Liu Juncheng, Application of the Horizontal Rotary-jet Grouting in Water-rich Sands of Urban Subway, Railway Construction Technology. 2010 (4) 55-58.

[2] Han Li, Application of horizontal rotary-jet grouting pile in subway super shallow tunnel of water sands, Guangdong Architecture Civil Engineering. 2004 (08) 76-78.

[3] Yang Haihong, Grouting and reinforcement technology of pebbly water-rich sands, Shanxi Architecture. 2007, 33(7) 333-334.

[4] Yang Hongshe, Application of horizontal rotary-jet grouting technology in reinforcement work of Xing Wangmao tunnel sands, Tunnel Construction. 2010, 30(1) 106-111.

[5] Xudong Zhao, Xingwen Liu, Improved Results on Stability of Continuous-Time Switched Positive Linear Systems, Automatics. 50(2): 614-621, 2014. 